\title{
Availability analysis of post-combustion carbon capture systems: minimum work input
}

\author{
N R McGlashan* and A J Marquis \\ Mechanical Engineering Department, Imperial College of Science, Technology, and Medicine, London, UK
}

The manuscript was received on 27 June 2006 and was accepted after revision for publication on 5 June 2007.

DOI: 10.1243/09544062JMES424

\begin{abstract}
This paper describes the availability analysis of a generic, post-combustion carbon capture plant. The analysis first establishes the minimum work input required in an ideal plant with a flue gas inlet temperature equal to the sink temperature. The analysis shows that the ideal work input is surprisingly low and that, roughly equal amounts of work are required to first separate and then compress the $\mathrm{CO}_{2}$ contained in a typical flue gas stream. The analysis is then extended to include the effects of variable inlet temperature and extraction efficiency. This extended analysis shows that there is a considerable quantity of available energy in the flue gas of a normal power station. Indeed, in principle, carbon capture is theoretically possible without any external work input for fuels of low carbon/hydrogen ratio such as heavy fuel oil and natural gas. When burning coal, the minimum work input would be significantly reduced if the flue gases' availability were utilized.

The final section of the paper compares the actual work input of a variety of carbon capture schemes found in the literature, with the minimum work input for an ideal process. This comparison shows that the techniques presently found in the literature have a low second-law efficiency.
\end{abstract}

Keywords: carbon capture, post-combustion, availability, minimum work input, second-law efficiency

\section{INTRODUCTION}

Carbon sequestration has become an accepted part of a global effort to reduce man's augmentation of the greenhouse effect to sustainable levels. Substantial research programmes, sponsored by both government and industry, have shown that the technique is both technically and economically feasible and has advantages when compared with many of the alternatives [1]. Current research on carbon sequestration technology concentrates on broadly two main areas: carbon capture and carbon storage. Traditionally the storage technology is not considered critical from a thermodynamic perspective [2]; the process of separating $\mathrm{CO}_{2}$ from the flue gas and its subsequent liquefaction (or compression) requires larger energy input.

\footnotetext{
*Corresponding author: Thermofluids Section, Mechanical Engineering Department, Imperial College, Exhibition Road, South Kensington, London SW7 2BX, UK. email:nrm@ic.ac.uk
}

Many commentators state that since the removal of $\mathrm{CO}_{2}$ from gas streams is an established practice in the chemical industry, the application to the power industry is simply a matter of transferring a mature technology $[3,4]$. There is undoubtedly logic in this position, however, the removal of $\mathrm{CO}_{2}$ from flue gas in a power station still represents a major technical challenge. This is partly due to the low partial pressure of $\mathrm{CO}_{2}$ in the flue gas, although, there are many techniques to deal with this situation [5]. However, another important factor is the economics of the power industry. The power industry does not have the luxury of producing a high value product. Additionally, it is increasingly one of intense competition and often subject to price shocks in one fuel sector and not another. Conversely, the chemical industry has the advantage that its products are generally of much higher value than energy, so there is less of an imperative for raising efficiency and minimizing capital cost. Additionally, in the chemical industry there is often a requirement for process 'robustness'. This can lead to 
relatively thermally inefficient, complicated, or capital intensive processes being justified.

Carbon sequestration cannot be achieved without a heavily integrated industry with huge investment on fixed equipment. Hence, to make carbon sequestration an industrial reality, rather than an academic curiosity, one of two things is required: Government intervention to reduce the risk of investors or a carbon capture process which is robust, reliable, thermally efficient, and above all cheap (both to build and operate) and hence reducing the risk of investors.

This series of papers, will attempt to analyse from first principles the loss mechanisms inherent in various carbon capture technologies and suggest possible routes for optimization. This paper starts the analysis by attempting to outline a thermodynamically sound basis for comparing the efficiency of different carbon capture cycles. Later papers will extend this analysis to include terms specific to two types of post-combustion carbon capture plant: physical and chemical absorption systems.

\section{ANALYSIS OF GENERIC CARBON CAPTURE PROCESS}

In this section the minimum work input required to separate $\mathrm{CO}_{2}$ from flue gas in an ideal postcombustion carbon capture plant will be evaluated. Figure 1 shows a diagram of an idealized scheme producing $\mathrm{CO}_{2}$ as a compressed liquid. To simplify the analysis it has been assumed that this generic process takes place isothermally. The flue gas is assumed to consist of nitrogen mixed with $\mathrm{CO}_{2}$ at standard temperature and pressure $\left(25^{\circ} \mathrm{C}\right.$ and 1.01 bar). This makes possible the assumption of burning pure carbon with complete combustion of the oxygen content of the air, however, the following analysis will show that this is not a limitation.

The first step in analysing this generic process is to calculate the minimum work input required. This will enable the second law efficiency of actual capture plant to be assessed. Reversible work input for

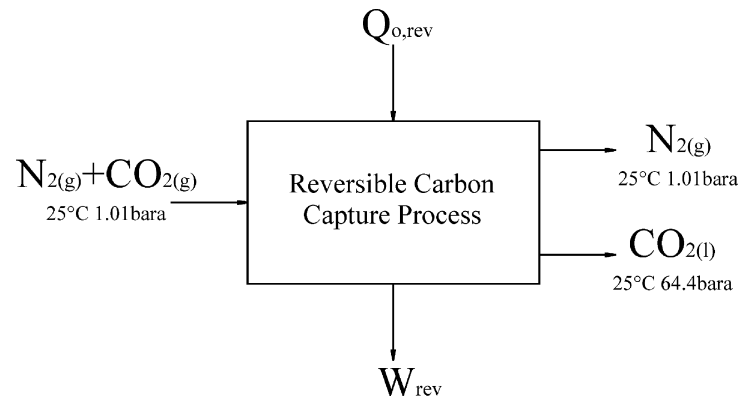

Fig. 1 Model of generic carbon capture process any steady flow process is the difference in the steady flow availability function of the streams entering and leaving the process $[6,7]$. Assuming kinetic and potential energy terms to be negligible and heat rejection to occur reversibly to an infinite reservoir at $T_{0}$, the reversible work is given by

$$
W_{\text {rev }}=\Delta H-Q_{0, \text { rev }}=\left(H_{\text {in }}-H_{\text {out }}\right)-T_{0}\left(S_{\text {in }}-S_{\text {out }}\right)
$$

which on a molar basis reduces to

$$
w_{\text {rev }}=\left(b_{\text {in }}-b_{\text {out }}\right)=\Delta b
$$

For multiple streams, equation (2) becomes

$$
w_{\text {rev }}=\sum_{j=1}^{J} m_{j, \text { in }} \cdot b_{j, \text { in }}-\sum_{k=1}^{K} m_{k, \text { out }} \cdot b_{k, \text { out }}
$$

where $j$ and $k$ refer to individual inlet and outlet streams, respectively.

To calculate the steady flow availability function of a given stream, values for the enthalpy and entropy are required. Carbon capture plant typically has streams entering and leaving that are mixtures of either gases or liquids. Ignoring liquid mixtures at this stage and assuming that ideal gas mixtures are formed, the enthalpy of a mixture of ideal gases on a molar basis is simply the mole fraction weighted average of the constituent's enthalpies, thus [6]

$$
h_{\text {mix }}(T)=\sum y_{i} \cdot h_{i}(T)+\sum y_{i} \cdot h_{i}^{0}
$$

where $h_{i}^{0}$ is the standard state enthalpy of component $i, h_{i}(T)$ the molar enthalpy of component $i$, and $y_{i}$ the mole fraction of component $i$.

The molar mixture entropy for a mixture of ideal gases is similar, but includes an extra term representing the ideal entropy of mixing, thus [6]

$$
\begin{aligned}
s_{\text {mix }}(T)= & \sum y_{i} \cdot s_{i}(T)+\sum y_{i} \cdot s_{i}^{0} \\
& +\Re\left(\sum y_{i} \cdot \ln \frac{1}{y_{i}}-\ln p_{\mathrm{r}}\right)
\end{aligned}
$$

where $p_{\mathrm{r}}=p / p^{0}, p$ the system pressure, $p^{0}$ the standard state pressure $=101.3 \mathrm{kPa}, s_{i}^{0}$ the standard state entropy of component $i$, and $s_{i}(T)$ the molar entropy at standard pressure of component $i$.

Combining equations (4) and (5) yields an expression for the molar steady flow availability function of 
an ideal mixture of ideal gases

$$
\begin{aligned}
b_{\text {mix }}= & \sum y_{i} \cdot h_{i}(T)-T_{0}\left[\sum y_{i} \cdot s_{i}(T)\right. \\
& \left.+\Re\left(\sum y_{i} \cdot \ln \frac{1}{y_{i}}-\ln p_{\mathrm{r}}\right)\right]
\end{aligned}
$$

The terms for standard state enthalpy and entropy in equations (4) and (5) have been ignored as these cancel in steady flow problems with no chemical reaction. Thus, for the generic carbon capture process shown in Fig. 1, the steady flow availability function of the incoming flue gas, per mole of $\mathrm{CO}_{2}$ entering the capture process is given by (dropping the $(T)$ on the entropies and enthalpies)

$$
\begin{aligned}
b_{\mathrm{in}}= & h_{\mathrm{CO}_{2, \mathrm{~g})}}+\frac{\left(1-y_{\mathrm{CO}_{2}}\right)}{y_{\mathrm{CO}_{2}}} h_{\mathrm{N}_{2,(\mathrm{~g})}} \\
& -T_{0}\left[s_{\mathrm{CO}_{2,(\mathrm{~g})}}+\frac{\left(1-y_{\mathrm{CO}_{2}}\right)}{y_{\mathrm{CO}_{2}}} s_{\mathrm{N}_{2, \mathrm{~g})}}\right. \\
& +\Re\left\{\ln \left(\frac{1}{y_{\mathrm{CO}_{2}}}\right)+\frac{\left(1-y_{\mathrm{CO}_{2}}\right)}{y_{\mathrm{CO}_{2}}} \ln \left(\frac{1}{\left(1-y_{\mathrm{CO}_{2}}\right)}\right)\right. \\
& \left.\left.-\frac{\ln p_{\mathrm{r}}}{y_{\mathrm{CO}_{2}}}\right\}\right]
\end{aligned}
$$

where $y_{\mathrm{CO}_{2}}$ is the initial mole fraction of $\mathrm{CO}_{2}$ in the flue gas stream.

The sum of the steady flow availability function of the two outlet streams is simpler to evaluate since, due to the complete separation of $\mathrm{CO}_{2}$ from the flue gas, there is no entropy of mixing term. In the following equation (8), the effect of pressure on the enthalpy and entropy of liquid $\mathrm{CO}_{2}$ has been assumed to be negligible. However, for completeness the enthalpy and entropy of liquid $\mathrm{CO}_{2}$ can be evaluated at the saturation pressure of $\mathrm{CO}_{2}$ if desired.

$$
\begin{aligned}
b_{\mathrm{out}}= & h_{\mathrm{CO}_{2, \mathrm{l})}}+\frac{\left(1-y_{\mathrm{CO}_{2}}\right)}{y_{\mathrm{CO}_{2}}} h_{\mathrm{N}_{2, \mathrm{~g})}} \\
& -T_{0}\left(s_{\mathrm{CO}_{2,(\mathrm{I})}}+\frac{\left(1-y_{\mathrm{CO}_{2}}\right)}{y_{\mathrm{CO}_{2}}}\left(s_{\mathrm{N}_{2,(\mathrm{~g})}}-\Re \ln p_{\mathrm{r}}\right)\right)
\end{aligned}
$$

Substituting equations (7) and (8) into equation (2) gives an expression for the reversible work of our generic process

$$
\begin{aligned}
w_{\mathrm{rev}}= & \left(h_{\mathrm{CO}_{2,(\mathrm{~g})}}-T_{0} s_{\mathrm{CO}_{2,(\mathrm{~g})}}\right)_{P_{\mathrm{in}}}-\left(h_{\mathrm{CO}_{2,(\mathrm{l})}}-T_{0} s_{\mathrm{CO}_{2,(\mathrm{l})}}\right)_{P_{\text {sat }, \text { out }}} \\
& -T_{0} \Re\left\{\ln \left(\frac{1}{y_{\mathrm{CO}_{2}}}\right)+\frac{\left(1-y_{\mathrm{CO}_{2}}\right)}{y_{\mathrm{CO}_{2}}}\right. \\
& \left.\times \ln \left(\frac{1}{\left(1-y_{\mathrm{CO}_{2}}\right)}\right)-\ln p_{\mathrm{r}}\right\}
\end{aligned}
$$

This result is notable as it only includes terms relating to $\mathrm{CO}_{2}$ and thus shows that the reversible work for 100 per cent $\mathrm{CO}_{2}$ separation is dependent only on the initial molar concentration of $\mathrm{CO}_{2}$ (assuming ideal gases and mixtures). Values of the flue gases' enthalpy and entropy are therefore not required, nor is the exact composition if the fuel's composition, combustion efficiency, and molar flowrates of the fuel and air entering the power station are known, since these can be used to evaluate the $\mathrm{CO}_{2}$ concentration of the flue gas. A complication is the presence of other condensable gases such as water, but this will be considered in section 3.2.

Equation (9) can be split into two terms that represent the work required in two separate operations: the work to overcome the entropy of mixing and the work required to liquefy the $\mathrm{CO}_{2}$, respectively

$$
w_{\mathrm{rev}}=w_{\mathrm{rev}, 1}+w_{\mathrm{rev}, 2}
$$

where, on a mass basis, the work to overcome the entropy of mixing between $\mathrm{CO}_{2}$ and the flue gas is given by

$$
\begin{aligned}
W_{\mathrm{rev}, 1}= & \frac{-T_{0} \Re}{M_{\mathrm{CO}_{2}}}\left\{\ln \left(\frac{1}{y_{\mathrm{CO}_{2}}}\right)+\frac{\left(1-y_{\mathrm{CO}_{2}}\right)}{y_{\mathrm{CO}_{2}}}\right. \\
& \left.\times \ln \left(\frac{1}{\left(1-y_{\mathrm{CO}_{2}}\right)}\right)-\ln p_{\mathrm{r}}\right\}
\end{aligned}
$$

This work input rises from zero at 100 per cent $\mathrm{CO}_{2}$ concentration, to infinity at 0 per cent $\mathrm{CO}_{2}$ concentration.

The second term for the work to liquefy the $\mathrm{CO}_{2}$ is given by (on a mass basis)

$$
\begin{aligned}
W_{\text {rev }, 2}= & \left(H_{\mathrm{CO}_{2,(\mathrm{~g})}}-T_{0} S_{\mathrm{CO}_{2,(\mathrm{~g})}}\right)_{P_{\text {in }}} \\
& -\left(H_{\mathrm{CO}_{2, \text { (l) }}}-T_{0} S_{\mathrm{CO}_{2,(\mathrm{l})}}\right)_{P_{\text {sat }, \text { out }}}
\end{aligned}
$$

This work input remains constant and for the conditions specified has the value

$$
W_{\text {rev }, 2}=-211.5 \mathrm{~kJ} / \mathrm{kg} \mathrm{CO}
$$

Figure 2 shows the combined minimum work inputs, per $\mathrm{kg}$ of captured $\mathrm{CO}_{2}$, of the first two operations, as functions of the initial $\mathrm{CO}_{2}$ mole fraction in the flue gas. The graph illustrates the relatively small amount of work required to achieve carbon capture in an ideal plant. Indeed, taking a typical coal burning power station, burning a coal with a gross heating value of $28 \mathrm{MJ} / \mathrm{kg}$ and a flue gas $\mathrm{CO}_{2}$ concentration of 11 per cent, the resulting reduction in station output is a manageable 1.34 percentage points.

A further simplification to the analysis can be achieved by splitting the liquefaction operation into two further operations (J. H. Horlock, 2005, personal communication), as shown in Fig. 3. Overall minimum 


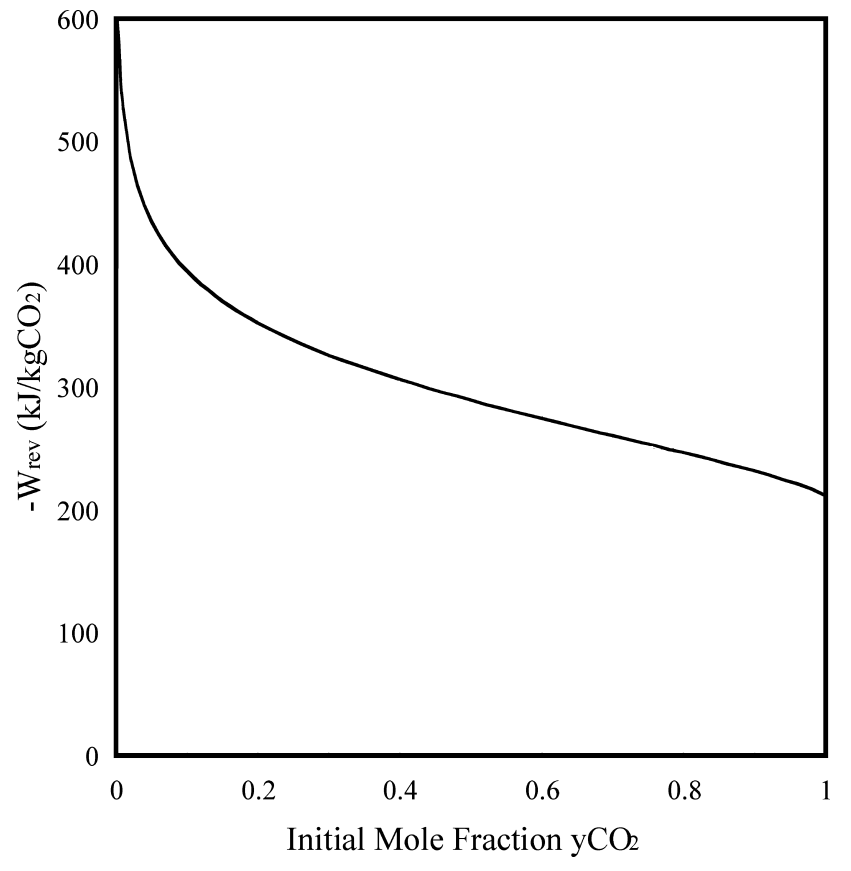

Fig. 2 Minimum work input in ideal post-combustion carbon capture cycle with 100 per cent capture efficiency

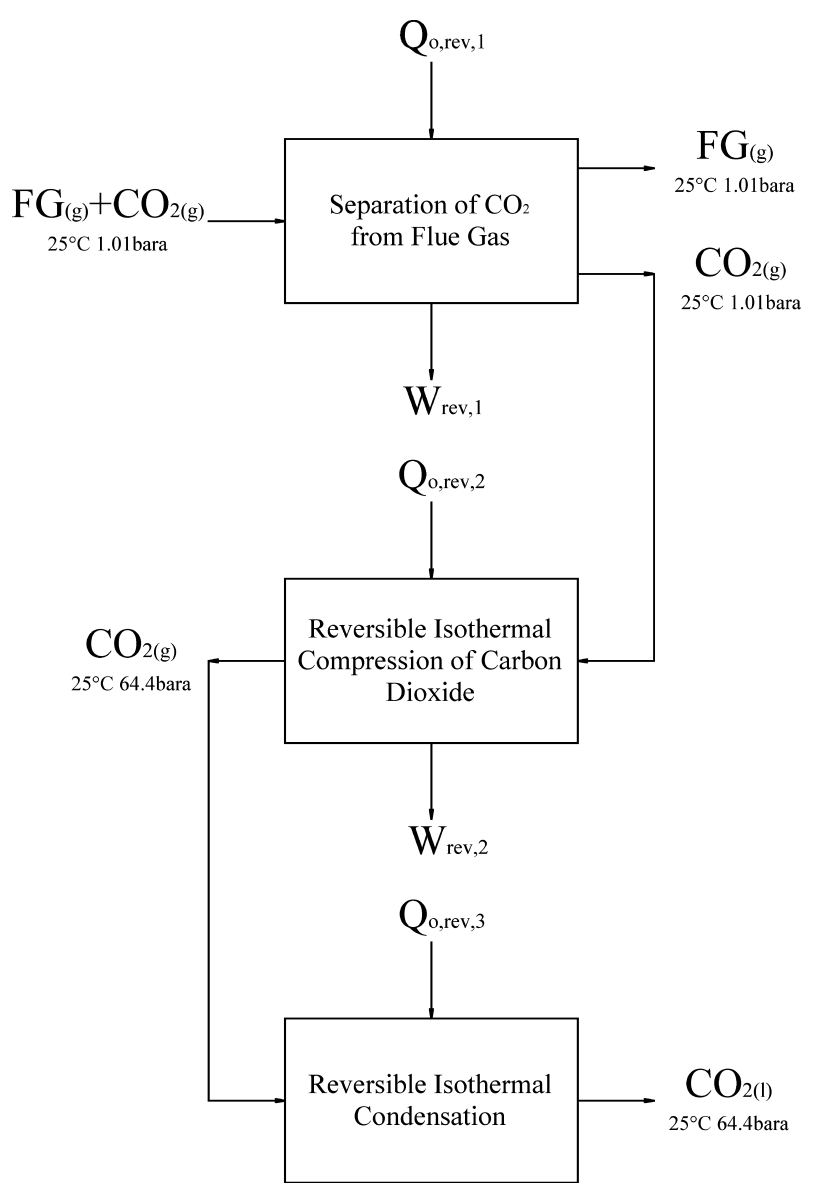

Fig. 3 Three-operation model of generic carbon capture process work input for our generic process is then given by

$$
W_{\mathrm{rev}}=W_{\mathrm{rev}, 1}+W_{\mathrm{rev}, 2,1}+W_{\mathrm{rev}, 2,2}
$$

where operation 2,1 is the isothermal compression of the separated $\mathrm{CO}_{2}$ to its saturation pressure at $T_{0}$

$$
\begin{aligned}
W_{\mathrm{rev}, 2,1}= & \left(H_{\mathrm{CO}_{2, \mathrm{~g})}}-T_{0} S_{\mathrm{CO}_{2,(\mathrm{~g})}}\right)_{P_{\mathrm{in}}} \\
& -\left(H_{\mathrm{CO}_{2,(\mathrm{~g})}}-T_{0} S_{\mathrm{CO}_{2,(\mathrm{~g})}}\right)_{P_{\text {sat }, \mathrm{out}}}
\end{aligned}
$$

and operation 2,2 is the isothermal condensation of the $\mathrm{CO}_{2}$ at its saturation pressure at $T_{0}$

$$
\begin{aligned}
W_{\mathrm{rev}, 2,2}= & \left(H_{\mathrm{CO}_{2,(\mathrm{~g})}}-T_{0} S_{\mathrm{CO}_{2,(\mathrm{~g})}}\right)_{P_{\mathrm{sat}, \text { in }}} \\
& -\left(H_{\mathrm{CO}_{2,(\mathrm{I})}}-T_{0} S_{\mathrm{CO}_{2,(\mathrm{l})}}\right)_{P_{\mathrm{sat}, \mathrm{out}}}
\end{aligned}
$$

Equation (15) must sum to zero since a steady flow, isobaric condensation process involves no shaft work, while the work potential of a heat rejection at $T_{0}$ is also zero. As a result, only equation (14) needs to be considered in the calculation of minimum work input. The advantage of these formulae is that there is no need to establish liquid enthalpies and entropies.

The magnitude of the two work input terms, given by equations (11) and (14), are roughly equivalent for $\mathrm{CO}_{2}$ concentrations found in a typical power station's flue gas. However, separating $\mathrm{CO}_{2}$ from the flue gas is of greater concern to a station designer than the subsequent compression process. This does not mean that there are not considerable losses during liquefying (or compressing) of many tons of $\mathrm{CO}_{2}$ vapour per minute, but these losses are independent of the initial concentration of $\mathrm{CO}_{2}$ in the flue gas and can be considered as a 'fixed cost' in thermodynamic terms. In addition, there is little scope for new ideas in the field of gas compression and condensation. Conversely, many of the methods traditionally used by chemical engineers to perform gas separation, exhibit significant entropy production [8] due to practical considerations. As an example, if we consider a carbon capture plant using a physical absorption process, the 'driving force' for mass transfer of $\mathrm{CO}_{2}$ from flue gas to absorbent is a difference in the fugacity of $\mathrm{CO}_{2}$ in the two streams. In principle this fugacity difference (which can be likened to a pressure drop) only needs to be sufficient for the entropy of mixing to be overcome; in practice, to avoid impossibly large contacting equipment, a compromise is made and a larger difference of fugacity is specified. This 'driving' difference in fugacity is in turn indicative of the avoidable part of the entropy production and results in physical absorption systems exhibiting much lower efficiencies in practice than theoretically obtainable. Similar arguments can be used to show that overcoming the entropy of mixing is likely to lead to avoidable irreversibilities in other types of capture plant. 


\section{GENERIC CAPTURE PROCESS WITH REALISTIC INLET AND OUTLET CONDITIONS}

Availability analysis in section 2 assumed that various streams enter or leave the carbon capture plant at sink temperature and that 100 per cent carbon capture is required. It is likely that carbon capture plant will be specified to capture less than 100 per cent of the $\mathrm{CO}_{2}$ contained in the flue gas. Further, it is usual for flue gas to be passed to any post-combustion scrubbing system at temperature far above ambient. To accommodate these variations in inlet and outlet conditions, further analyses are required.

\subsection{Capture efficiency}

$\mathrm{CO}_{2}$ capture efficiency can be defined thus

$$
\eta_{\mathrm{c}}=\frac{\text { Moles }_{\text {captured }}}{\text { Moles }_{\text {in }}}
$$

Allowing for capture efficiency complicates the availability analysis of our generic process since there will now be an entropy of mixing term for both the flue gas entering and leaving the capture plant. Nonetheless, a similar analysis to that of section 2 can be conducted. The availability of the inlet stream is still given by equation (7), whereas that of the outlet streams is given by

$$
\begin{aligned}
b_{\text {out }}= & \left(1-\eta_{\mathrm{c}}\right)\left(h_{\mathrm{CO}_{2,(\mathrm{~g})}}-T_{0} s_{\mathrm{CO}_{2,(\mathrm{~g})}}\right)+\eta_{\mathrm{c}}\left(h_{\mathrm{CO}_{2, \mathrm{I}}}\right. \\
& \left.-T_{0} s_{\mathrm{CO}_{2, \mathrm{I}}}\right)+\frac{\left(1-y_{\mathrm{CO}_{2}}\right)}{y_{\mathrm{CO}_{2}}}\left(h_{\mathrm{N}_{2,(\mathrm{~g})}}-T_{0} s_{\mathrm{N}_{2,(\mathrm{~g})}}\right) \\
& -\Re T_{0}\left\{\left(1-\eta_{\mathrm{c}}\right) \cdot \ln \frac{\left(1-\eta_{\mathrm{c}} y_{\mathrm{CO}_{2}}\right)}{\left(1-\eta_{\mathrm{c}}\right) y_{\mathrm{CO}_{2}}}+\frac{\left(1-y_{\mathrm{CO}_{2}}\right)}{y_{\mathrm{CO}_{2}}}\right. \\
& \left.\cdot \ln \frac{\left(1-\eta_{\mathrm{c}} y_{\mathrm{CO}_{2}}\right)}{\left(1-y_{\mathrm{CO}_{2}}\right)}-\frac{\left(1-\eta_{\mathrm{c}} y_{\mathrm{CO}_{2}}\right) \ln p_{\mathrm{r}}}{y_{\mathrm{CO}_{2}}}\right\}
\end{aligned}
$$

Combining equations (7) and (17) and collecting terms gives the minimum work input per $\mathrm{kg}$ of captured $\mathrm{CO}_{2}$

$$
\begin{aligned}
W_{\mathrm{rev}, \mathrm{c}}= & \frac{\left(b_{\mathrm{in}}-b_{\mathrm{out}}\right)}{\eta_{\mathrm{c}} M_{\mathrm{CO}_{2}}}=\left(H_{\mathrm{CO}_{2,(\mathrm{~g})}}-H_{\mathrm{CO}_{2,(\mathrm{l})}}\right) \\
& -T_{0}\left(S_{\mathrm{CO}_{2,(\mathrm{~g})}}-S_{\mathrm{CO}_{2,(\mathrm{l})}}\right)-\frac{\Re T_{0}}{\eta_{\mathrm{c}} M_{\mathrm{CO}_{2}}} \\
& \times\left\{\ln \left(\frac{1}{y_{\mathrm{CO}_{2}}}\right)+\frac{\left(1-\eta_{\mathrm{c}} y_{\mathrm{CO}_{2}}\right)}{y_{\mathrm{CO}_{2}}} \ln \frac{1}{\left(1-\eta_{\mathrm{c}} y_{\left.\mathrm{CO}_{2}\right)}\right.}\right. \\
& \left.+\left(1-\eta_{\mathrm{c}}\right) \ln \left(1-\eta_{\mathrm{c}}\right) y_{\mathrm{CO}_{2}}-\eta_{\mathrm{c}} \ln p_{\mathrm{r}}\right\}
\end{aligned}
$$

Note, that with a capture efficiency of 100 per cent, equation (18) is equivalent to equation (9).

As before, equation (18) can be split into two terms representing, respectively: the minimum work to liquefy the captured $\mathrm{CO}_{2}$ and the minimum work to overcome the entropy of mixing. The latter work input is given below by equation (19), which is plotted in Fig. 4 for a number of different capture efficiencies

$$
\begin{aligned}
W_{\text {mix }}= & -\frac{\Re T_{0}}{\eta_{\mathrm{c}} M_{\mathrm{CO}_{2}}}\left\{\ln \left(\frac{1}{y_{\mathrm{CO}_{2}}}\right)+\frac{\left(1-\eta_{\mathrm{c}} y_{\mathrm{CO}_{2}}\right)}{y_{\mathrm{CO}_{2}}}\right. \\
& \times \ln \frac{1}{\left(1-\eta_{\mathrm{c}} y_{\mathrm{CO}_{2}}\right)}+\left(1-\eta_{\mathrm{c}}\right) \\
& \left.\times \ln \left(1-\eta_{\mathrm{c}}\right) y_{\mathrm{CO}_{2}}-\eta_{\mathrm{c}} \ln p_{\mathrm{r}}\right\}
\end{aligned}
$$

Figure 4 shows that there is a marked reduction in the required work input as capture efficiency is reduced, though it seems unlikely that this fact can be utilized in any practical way. This effect can be explained by considering the change in the Gibbs function of the various streams and their components. At first sight, a separation process should increase the Gibbs function of both the flue gas and the $\mathrm{CO}_{2}$ as they are both purified - hence the need for work input. However, although the Gibbs function of any $\mathrm{CO}_{2}$ extracted is clearly increased, the $\mathrm{CO}_{2}$ that remains in the flue gas experiences a further dilution process and there is a fall in its Gibbs function. This dilution process need not, however, result in any lost work, since it occurs simultaneously with the extraction process the two processes are coupled and the fall in Gibbs function of the $\mathrm{CO}_{2}$ left in the flue gas reduces the work input required to extract the remainder. Another way of viewing this, is that the partial pressure of the $\mathrm{CO}_{2}$ that remains in the flue gas, provides a driving force to help extract the remainder.

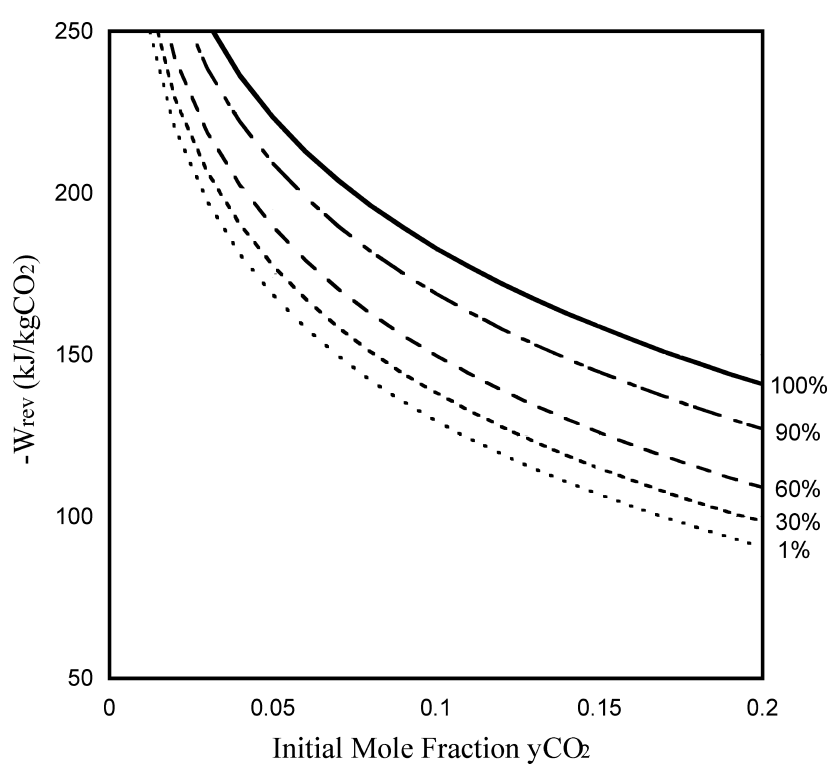

Fig. 4 Minimum work input to overcome the entropy of mixing between $\mathrm{CO}_{2}$ and flue gas versus initial $\mathrm{CO}_{2}$ mole fraction at different capture efficiencies 


\subsection{Temperature of flue gas}

Flue gases are passed to the chimney of typical power stations at temperatures varying from circa $150^{\circ} \mathrm{C}$ in a heavy-oil fired station [9], to circa $80^{\circ} \mathrm{C}$ in a natural gas installation [10]. Extra useful work can, in principle, be produced as a result of reducing this discharge temperature prior to admission to the capture plant using some form of thermodynamic cycle. The quantity of available energy in the flue gas is not inconsiderable due to the significant amount of latent heat of the steam it contains, as well as the flue gases' sensible heat. This available energy is normally rejected from power plants with the chimney gases. Nonetheless, it is a requirement of many carbon capture schemes that the flue gas temperature is reduced from its inlet level to a point at which absorbent degradation does not occur [11]. Further, it is not improbable that some form of capture process will be conceived in the future that makes use of this available energy to some extent. Therefore, it was decided that a further analysis was required to take the potential work output into account.

In the analysis in sections 2 and 3.1, the terms for the flue gases' enthalpy cancelled and did not appear in equations (9) or (18). In addition, the only term associated with the flue gases' entropy in these equations, was that of the entropy of mixing and this was expressed purely in terms of the initial mole fraction of $\mathrm{CO}_{2}$ in the flue gas. However, if the flue gases' inlet temperature is different from the temperature at which the capture process is assumed to take place, these simplifications cannot be made; a more complete analysis is required. To simplify the resulting analysis, the capture plant can be broken into two separate sections: the first, cooling the flue gas to sink temperature, while the second is identical to the generic carbon capture process already analysed. Figure 5 shows the relevant diagram of the separate cooling plant.

The analysis of this process is similar to that of the process shown in Fig. 1. For simplicity, all the water is assumed to exit as condensate and a mixture of $\mathrm{N}_{2}$, $\mathrm{O}_{2}, \mathrm{SO}_{2}$, and $\mathrm{CO}_{2}$ will then pass to the carbon capture plant. Applying equation (3) and assuming ideal gases,

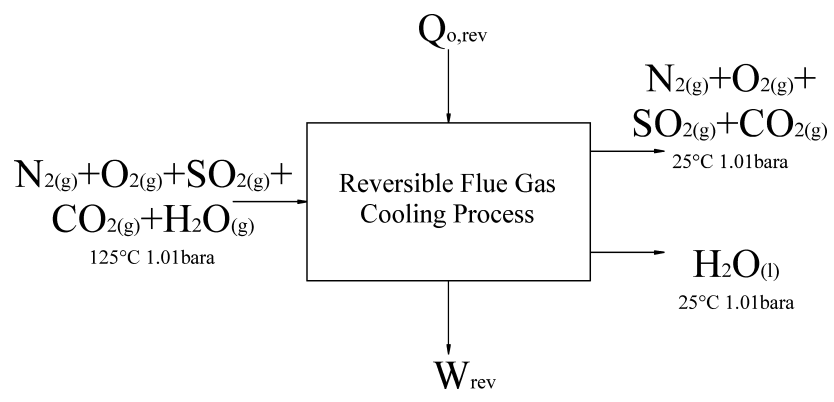

Fig. 5 Model of pre-cooling process the minimum work per $\mathrm{kg}$ of $\mathrm{CO}_{2}$ entering the plant, is given by

$$
\begin{aligned}
W_{\mathrm{rev}}= & \sum_{i}^{I} \frac{y_{\mathrm{i}}}{y_{\mathrm{CO}_{2}}}\left[\left(H_{i,(\mathrm{~g})}-T_{0} S_{i,(\mathrm{~g})}\right)_{\text {in }}\right. \\
& \left.-\left(H_{i,(\mathrm{~g})}-T_{0} S_{i,(\mathrm{~g})}\right)_{\mathrm{out}}\right] \\
& +\frac{y_{\mathrm{H}_{2} \mathrm{O}}}{y_{\mathrm{CO}_{2}}}\left[\left(H_{\mathrm{H}_{2} \mathrm{O},(\mathrm{g})}-T_{0} S_{\mathrm{H}_{2} \mathrm{O},(\mathrm{g})}\right)_{\mathrm{in}}\right. \\
& \left.-\left(H_{\mathrm{H}_{2} \mathrm{O},(\mathrm{l})}-T_{0} S_{\mathrm{H}_{2} \mathrm{O},(\mathrm{l})}\right)_{\mathrm{out}}\right] \\
& -\frac{T_{0} \Re}{M_{\mathrm{CO}_{2}}}\left\{\left(\frac{1-y_{\mathrm{H}_{2} \mathrm{O}}}{y_{\mathrm{CO}_{2}}}\right) \ln \left(\frac{1}{1-y_{\mathrm{H}_{2} \mathrm{O}}}\right)\right. \\
& \left.+\frac{y_{\mathrm{H}_{2} \mathrm{O}}}{y_{\mathrm{CO}_{2}}} \ln \left(\frac{1}{y_{\mathrm{H}_{2} \mathrm{O}}}\right)-\left(1-y_{\mathrm{H}_{2} \mathrm{O}}\right) \ln p_{\mathrm{r}}\right\}
\end{aligned}
$$

Summation in equation (20) includes terms that represent the work extractable due to the sensible heat of the $\mathrm{N}_{2}, \mathrm{O}_{2}, \mathrm{SO}_{2}$, and $\mathrm{CO}_{2}$, respectively. The next term represents the work extractable due to the sensible and latent heats of the steam. The last term represents the work required to overcome the entropy of mixing between the steam and the remainder of the flue gas during the condensation process.

To illustrate the use of this equation and also show the influence of a fuel's hydrogen content on plant performance, the minimum work input for a combined flue gas cooling and carbon capture plant has been calculated for three idealized fuels. The fuels are assumed to have the following empirical formulae [12]

Coal: $\mathrm{C}_{100} \mathrm{H}_{76} \mathrm{O}_{10} \mathrm{~N}_{3}$

Heavy fuel oil: $\mathrm{C}_{44} \mathrm{H}_{69} \mathrm{~S}_{0.75}$

Natural gas: $\mathrm{CH}_{4}$

The products of combustion of these fuels burning in dry air are represented by the reaction formulae given below. In each case $Z$ represents the equivalence ratio

$$
\begin{gathered}
Z \mathrm{C}_{100} \mathrm{H}_{76} \mathrm{O}_{10} \mathrm{~N}_{3}+114 \mathrm{O}_{2}+\frac{3002}{7} \mathrm{~N}_{2} \rightarrow 100 Z \mathrm{CO}_{2} \\
+38 Z \mathrm{H}_{2} \mathrm{O}+114(1-Z) \mathrm{O}_{2}+\left(\frac{3002}{7}+\frac{3}{2} Z\right) \mathrm{N}_{2}
\end{gathered}
$$

$$
\begin{aligned}
& Z \mathrm{C}_{44} \mathrm{H}_{69} \mathrm{~S}_{0.75}+62 \mathrm{O}_{2}+\frac{4898}{21} \mathrm{~N}_{2} \rightarrow 44 Z \mathrm{CO}_{2} \\
& +\frac{69}{2} Z \mathrm{H}_{2} \mathrm{O}+\frac{3}{4} Z \mathrm{SO}_{2}+62(1-Z) \mathrm{O}_{2}+\frac{4898}{21} \mathrm{~N}_{2} \\
& Z \mathrm{CH}_{4}+2 \mathrm{O}_{2}+\frac{158}{21} \mathrm{~N}_{2} \rightarrow Z \mathrm{CO}_{2}+2 Z \mathrm{H}_{2} \mathrm{O} \\
& \quad+2(1-Z) \mathrm{O}_{2}+\frac{158}{21} \mathrm{~N}_{2}
\end{aligned}
$$

Figure 6 shows a plot of the minimum work input calculated for these reference fuels as a function of 


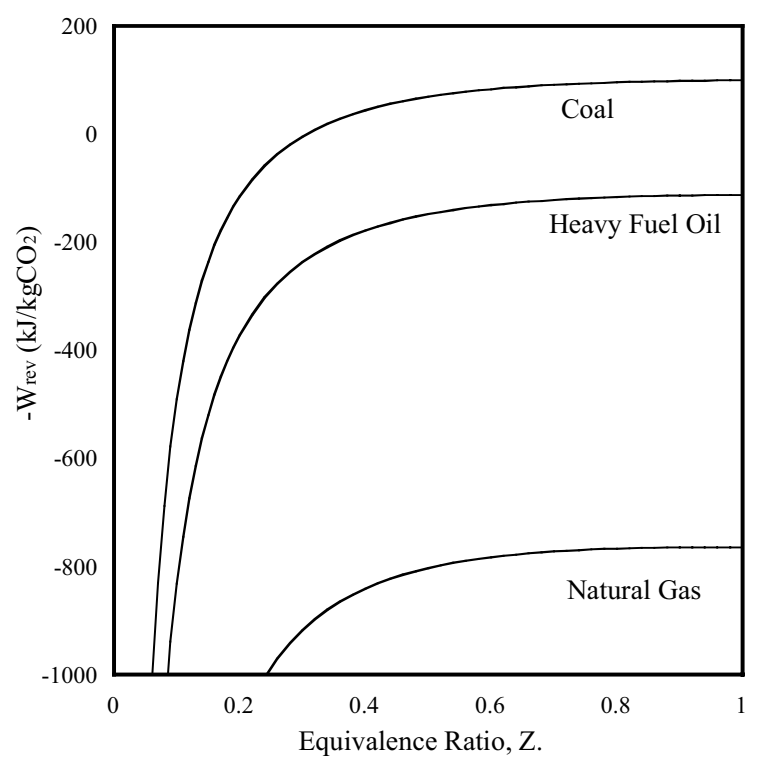

Fig. 6 Minimum work input in ideal post-combustion carbon capture cycle with flue gas inlet temperature of $125^{\circ} \mathrm{C}$ for three different fuels

the equivalence ratio, with an initial flue gas temperature of $125^{\circ} \mathrm{C}$. The work input is per $\mathrm{kg}$ of $\mathrm{CO}_{2}$ captured. These plots show the aggregate of equations (18) and (20) for different fuels, with a capture efficiency of 90 per cent. For all three fuels, at low equivalence ratio there is the potential for a significant net power output due to the available energy in the flue gas stream. This effect is partly due to the sensible heat of the excess of nitrogen and oxygen that exist in lean combustion systems - a phenomenon well known to the boiler-making industry [13]. However, even under stoichiometric conditions, the work input required to perform carbon capture is considerably less than it would be if the available energy, carried by the flue gas, had not been considered. A significant part of this available energy is due to the latent heat of the steam in the flue gas. As a result, for fuels with low carbon/hydrogen ratio, a net work output is theoretically obtainable at any equivalence ratio.

There are clearly immense practical difficulties in converting the available energy of the flue gas to shaft work. More likely is that the available energy might be used to provide part of the heat requirement in, say, solvent regeneration. Nonetheless, the analysis indicates the large amount of availability wasted in power stations which discharge hot flue gas straight into the atmosphere and particularly those operating with low overall fuel/air ratio such as combined cycle gas turbine plant.

\section{EFFICIENCY OF POST-COMBUSTION CARBON CAPTURE PROCESSES}

Availability analysis conducted in preceding sections has established the minimum work input required in a generic post-combustion carbon capture plant. This section will compare a number of different carbon capture processes which have been proposed in the literature, with the generic plant considered as a benchmark.

The literature does not usually contain sufficient data to establish the exact flows of heat and work in a given plant. Therefore, a simpler method of comparison has been adopted here which looks at the reduction in power station output between a conventional station and one with carbon capture, since these values usually are available in the literature. This reduction in output is then compared with the work input for the generic carbon capture plant, as given by equation (18), running at an equivalent flue gas $\mathrm{CO}_{2}$ concentration. The resulting carbon capture cycle efficiency has been thus defined as

$$
\eta_{\mathrm{ccc}}=\frac{W_{\mathrm{rev}}}{\Delta W}
$$

$\Delta W$ is the difference in power output between two power stations, with and without carbon capture plant, which are otherwise identical.

Defining efficiency in this way fails to account for the available energy in the flue gas according to equation (20). However, if the flue gases' available energy was considered as a credit to the capture plant, this would lead to anomalies; Fig. 6 shows that the ideal work input may cross through zero, which would lead to

Table 1 A comparison of different post-combustion carbon capture processes

\begin{tabular}{|c|c|c|c|c|c|c|}
\hline & Units & $\begin{array}{l}\text { Frosting } \\
\text { cryogenic cycle } \\
\text { (refrigeration } \\
\text { system COP }=0.55 \text { ) }\end{array}$ & $\begin{array}{l}\text { Frosting } \\
\text { cryogenic cycle } \\
(\text { refrigeration } \\
\text { system COP }=0.41 \text { ) }\end{array}$ & $\begin{array}{l}\text { Sub-critical } \\
\text { PF plant with } \\
\text { amine capture }\end{array}$ & $\begin{array}{l}\text { Sub-critical } \\
\text { PF plant with } \\
\text { amine capture }\end{array}$ & $\begin{array}{l}\text { Sub-critical } \\
\text { PF plant with } \\
\text { seawater capture }\end{array}$ \\
\hline Cost of capture & $\mathrm{MJ} / \mathrm{kg} \mathrm{CO} 2$ & 1.224 & 1.708 & 1.219 & 1.18 & 2.526 \\
\hline $\begin{array}{l}\text { Estimated flue gas } \mathrm{CO}_{2} \\
\text { Minimum work input: }\end{array}$ & $\begin{array}{l}\text { Mole fraction } \\
\mathrm{MJ} / \mathrm{kg} \mathrm{CO} 2\end{array}$ & $13.70 \%$ & $13.70 \%$ & $10.70 \%$ & $10.70 \%$ & $11.20 \%$ \\
\hline Equation (18) with $\eta_{\mathrm{c}}=90 \%$ & & 0.361 & 0.361 & 0.376 & 0.376 & 0.373 \\
\hline $\begin{array}{l}\eta_{\mathrm{ccc}} \\
\text { Reference }\end{array}$ & & $\begin{array}{l}29.48 \% \\
{[14]}\end{array}$ & $21.13 \%$ & $\begin{array}{l}30.82 \% \\
{[15]}\end{array}$ & $\begin{array}{l}31.84 \% \\
{[\mathbf{1 6}]}\end{array}$ & $\begin{array}{l}14.77 \% \\
{[17]}\end{array}$ \\
\hline
\end{tabular}

COP, coefficient of performance; PF, pulverized fuel. 
meaningless values of efficiency. In addition, since it is unlikely that the flue gases' available energy would be converted to work without the capture plant, it seems reasonable to ignore the contribution that the flue gases' available energy could make when assessing the viability of a particular scheme.

Table 1 includes the actual work input and carbon capture cycle efficiency for a number of different capture processes. Each process was analysed by the respective authors with a capture efficiency of 90 per cent. The processes selected all involve the post-combustion removal of $\mathrm{CO}_{2}$ from flue gas and use chemical absorption, physical absorption or freezing methods.

As can be seen from Table 1, all of the carbon capture techniques presented have a low second-law efficiency. Of note, however, is the especially poor performance of seawater absorption, despite the fact that such systems are not required to liquefy the $\mathrm{CO}_{2}$, since the seawater $/ \mathrm{CO}_{2}$ solution can be disposed of directly into the oceans. Nonetheless, the figures clearly indicate that there must be significant entropy production taking place in the absorption section of this type of plant. This may be due to the pressure losses or other forms of lost work generation.

\section{CONCLUSION}

In the current paper an analysis has been conducted on the minimum work requirement of a generic post-combustion carbon capture plant. The analysis showed that surprisingly little work input is required in the separation and compression stages of such systems. The model was extended to consider the effect of reduced capture efficiency and also the considerable amount of available energy contained in typical flue gas as it is passed to the capture process. It was shown that, rather than work input, it is theoretically possible to achieve a work output from post-combustion capture plant. This is due to the large amount of sensible and latent heat contained in the flue gas.

In the final part of the paper a comparison was made of different types of carbon capture plant. This section showed that all of the post-combustion systems, presently being researched, have poor performance. Of note however, is the especially poor performance of seawater absorption systems.

The next paper in this series, [18], will examine the lost work generation inherent to carbon capture systems in general. In particular, an extension to the analysis conducted above will be undertaken, which considers the unavoidable lost work inherent to mixing processes, both with and without chemical reaction. The analysis of the unavoidable irreversibility will be complemented by consideration of the likely external irreversibility. The conclusion of the paper will be suggestions of possible means of reducing the lost work generation to a minimum in carbon capture processes.

\section{ACKNOWLEDGEMENTS}

The authors would like to acknowledge the assistance of Sir John Horlock for suggestions relating to an earlier version of this paper. The authors are also grateful to Dr Shaun Crofton for proof reading draft versions of this paper.

\section{REFERENCES}

1 DTI. A strategy for developing carbon abatement technologies for fossil fuel use. Report of carbon abatement technologies programme, DTI, UK Government, 2005.

2 Wong, S. and Bioletti, R. Carbon dioxide separation technologies. Alberta Research Council, 2002.

3 Chakravarti, S., Gupta, A., and Hunek, B. Advanced technology for the capture of carbon dioxide from flue gas. First National Conference on Carbon sequestration, Washington, DC, 15-17 May 2001.

4 Singh, D. J., Croiset, E., Douglas, P. L., and Douglas, M. A. $\mathrm{CO}_{2}$ capture options for an existing coal fired power plant $\mathrm{O}_{2} / \mathrm{CO}_{2}$ recycle combustion vs. amine scrubbing. First National Conference on Carbon sequestration, Washington, DC, 15-17 May 2001.

5 Kohl, A. and Nielsen, R. Gas purification, 5th edition, 1997, pp. 62-98 (Gulf Publishing Company, Houston, TX).

6 Winterbone, D. E. Advanced thermodynamics for engineers, 1st edition, 1997, p. 65 (Arnold, London).

7 Horlock, J. H. Combined power plants - including combined cycle gas turbine (CCGT) plants, 2nd edition, 2002, p. 31 (Krieger Publishing Company, Malabar, FL).

8 Kotas, T. J. The exergy method of thermal plant analysis, 1st edition, 1985, p. 139 (Butterworths, London).

9 CEGB. Advances in power station construction, 1st edition, 1986, p. 153 (Pergamon Press, Oxford).

10 Kehlhofer, R., Bachmann, R., Nielson, H., and Warner, J. Combined-cycle gas and steam turbine power plants, 2nd edition, 1999, pp. 58-65 (Penwell, Tulsa).

11 Gibbins, J. R., Crane, R. I., Lambropoulos, D., Booth, C., Roberts, C. A., and Lord, M. Maximising the effectiveness of post combustion $\mathrm{CO}_{2}$ capture systems. In Proceedings of the 7th International Conference on Greenhouse gas control technologies, 2004, vol. 1 (Peer reviewed papers and plenary presentations).

12 Clark, G. H. Industrial and marine fuels reference book, 1st edition, 1988, pp. 7/13-7/14 (Butterworths, London).

13 Williams, J. N. Steam generation, 4th edition, 1953, p. 201 (George Allen and Unwin Ltd., London).

14 Clodic, D. and Younes, M. A new method for $\mathrm{CO}_{2}$ capture: frosting $\mathrm{CO}_{2}$ at atmospheric pressure. In Proceedings of the 6th International Conference on Greenhouse gas control technologies, 2002, pp. 155-160.

15 Gibbins, J. R. and Crane, R. Principles and performance limits for integrating amine scrubbing with coal and gas fired power plants. Report on 6th IEA GHG 
Workshop, International Test Network for $\mathrm{CO}_{2}$ Capture, Trondeheim, Norway. IEA GHG, Cheltenham, 8-9 March 2004.

16 Rubin, E. S., Rao, A. B., and Chen, C. Comparative assessments of fossil fuel power plants with $\mathrm{CO}_{2}$ capture and storage. In Proceedings of the 7th International Conference on Greenhouse gas control technologies, 2004, vol. 1 (peer reviewed papers and plenary presentations).

17 Göttlicher, G. The energetics of carbon dioxide capture in power plants. US Department of Energy, Office of Fossil Energy, National Energy Technology Laboratory, 2004.

18 McGlashan, N. R. and Marquis, A. J. Availability analysis of post-combustion carbon capture systems: unavoidable irreversibilities (in preparation).

\section{APPENDIX}

\section{Notation}

$b$

$B$

FG

$h$

$h^{0}$

$H$

$m_{i}$

$\mathrm{M}_{i}$

$p$

$\Re$

$s$

$s^{0}$

$S$ molar steady flow availability

function

steady flow availability

function - mass basis

flue gas

molar enthalpy

standard state molar enthalpy

enthalpy - mass basis

moles of species $i$

molecular weight of species $i$

pressure

universal gas constant

$=8.3141 \mathrm{~kJ} / \mathrm{kmol} \mathrm{K}$

molar entropy

standard state molar entropy

entropy - mass basis
$T$

$w_{\text {rev }}$

$W_{\text {rev }}$

$y_{i}$

Z

$\eta_{\mathrm{c}}$

$\eta_{\mathrm{ccc}}$

Subscripts

c

cr

(g)

$i$

in

thermodynamic temperature minimum work - mole basis minimum work - mass basis vapour phase mole fraction species $i$

equivalence ratio $=$ theoretical $/$ actual air flow

capture efficiency

carbon capture cycle efficiency

of capture process (as in efficiency)

control region (volume)

gaseous state

generic species reference

of stream flowing into process or operation

j

$k$

streams into process or operation

streams out of process or opera-

tion

(l) liquid state

mix mixture property

out of stream flowing out of process or operation

rev of reversible process or operation

sat saturation property

Superscripts

0

standard state: gas at $1.01 \mathrm{bar}$, $298 \mathrm{~K}$ 
